\title{
AS ESTRATÉGIAS DE REPRODUÇÃO SOCIAL DOS AGRICULTORES FAMILIARES DAS COMUNIDADES RURAIS DO MUNICÍPIO DE CATALÃO (GO) ${ }^{1}$ \\ STRATEGIES OF SOCIAL REPRODUCTION OF FAMILY FARMERS OF THE RURAL COMMUNITIES OF CATALÃO (GO)
}

\author{
Juniele Martins Silva ${ }^{1}$ Rosangela Aparecida de Medeiros Hespanhol ${ }^{1}$ \\ ${ }^{1}$ Universidade Estadual Paulista "Júlio de Mesquita Filho" (UNESP), Presidente Prudente, SP, Brasil
}

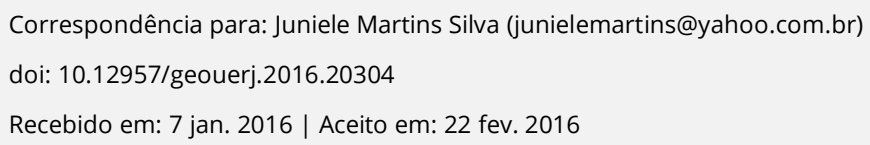

\section{RESUMO}

O meio rural brasileiro passou por intensas transformações a partir, principalmente, da década de 1970, em virtude do processo de modernização da agricultura. Esse processo ocorreu de forma desigual, favorecendo os produtos destinados à exportação, às regiões Sul, Sudeste e, posteriormente, ao Centro-Oeste e aos grandes e médios produtores rurais. Nesse contexto, os agricultores familiares, de pequeno porte, foram excluídos do processo modernizante, tendo acionado diversas estratégias que possibilitam a sua reprodução social. Com o objetivo de compreender as principais características da agricultura familiar, dando ênfase às estratégias de reprodução social empreendidas, propõe-se o presente artigo. Em termos empíricos, deu-se foco aos agricultores familiares das comunidades rurais de Custódia, Ribeirão, São Domingos e Tambiocó, no município de Catalão (GO). Para o desenvolvimento do trabalho, foram realizadas: revisão teórica; e pesquisa empírica nas comunidades rurais de Custódia (onde moram 54 famílias), Ribeirão (60 famílias), São Domingos (51 famílias) e Tambiocó (51 famílias), sendo aplicados, respectivamente, 19 (35,18\%), 21 (35,00\%), 17 (33,33\%) e 18 (35,29\%) formulários de entrevista com os agricultores familiares que residem nestas localidades.

Palavras-chave: Agricultura familiar. Estratégias de reprodução social. Lugar. Comunidades rurais. Município de Catalão (GO).

\section{ABSTRACT}

The rural areas in Brazil have undergone sweeping changes from mainly the 1970s, in response to the agricultural modernization process. This occurred unequally, favoring products for export, the South, Southeast and, subsequently, Midwest of Brazil and the large and medium farmers. In this context, the smallholder farmers were excluded of modernizing process, having employed various strategies which allow their social reproduction. With de purpose to understand the main characteristics of family farming, giving emphasis to undertaken social reproduction strategies, this paper is proposed. Empirically, there was focus to family farmers in rural communities Custódia, Ribeirão, São Domingos and Tambiocó in the municipality of Catalão (GO). For the development of this study, there have been literature review; desk research and empirical research in rural communities Custódia (inhabited by 54 families), Ribeirão (60 families), São Domingos (51 families) and Tambiocó (51 families), being applied, respectively, 19 (35.18\%), 21 (35.00\%), 17 (33.33\%) and 18 (35.29\%) interview forms with family farmers residing in these localities.

Keywords: Family farming. Strategies of social reproduction. Place. Rural communities. Municipality of Catalão (GO).

\section{INTRODUÇÃO}

\footnotetext{
${ }^{1} \mathrm{O}$ artigo é resultado da pesquisa de Doutorado realizada no Programa de Pós-graduação em Geografia da FCT/UNESP de Presidente Prudente, intitulado "As estratégias de reprodução social dos agricultores familiares das comunidades rurais do município de Catalão (GO)”.
} 
O meio rural brasileiro, a partir da década de 1970, passou por intensas transformações, decorrentes do processo de modernização da agricultura. Esse processo teve por intuito aumentar a produção e a produtividade agrícola, mediante a utilização de insumos, máquinas e implementos modernos. Deste modo, o Estado fez investimentos em infraestrutura, criação do Sistema Nacional de Crédito Rural e pesquisas por meio da Empresa Brasileira de Pesquisa Agropecuária (Embrapa), dentre outros.

Todavia, foi na década de 1980 que as áreas do Cerrado, em particular o estado de Goiás e o município de Catalão foram incorporados ao processo de expansão da modernização da agricultura. Assim, a partir desse período, os governos federal, estaduais e municipais instauraram medidas de incentivo para essas áreas. Vale salientar o papel da pesquisa agronômica e do crédito rural.

De modo geral, esse processo de modernização da agricultura não ocorreu de forma homogênea. Assim sendo, privilegiou alguns cultivos, sobretudo, aqueles direcionados à exportação e à produção de combustíveis (cana-de-açúcar); favoreceu os médios e grandes produtores rurais e aqueles situados nas regiões Sul e Sudeste; e a mecanização não atingiu todas as etapas do processo de produção. Essa realidade é verificada em Goiás, assim os investimentos foram direcionados para os grandes e médios produtores rurais em detrimento dos pequenos, concentrou-se na porção Sul do estado e incentivou o cultivo de alguns produtos como soja, milho e cana-de-açúcar.

De modo geral, os agricultores familiares para permanecerem no meio rural têm acionado diversas estratégias de reprodução social. Uma das estratégias é a diversificação de produtos agrícolas e a criação de animais, como se verifica no município de Catalão que se constitui no recorte espacial da pesquisa. Verifica-se que as políticas públicas como o Programa Nacional de Fortalecimento da Agricultura Familiar (PRONAF) e Programa Nacional de Alimentação Escolar (PNAE) também, contribuem de forma significativa para a reprodução social do grupo.

Nesse contexto, o objetivo geral do artigo é compreender as principais características da agricultura familiar, dando ênfase nas estratégias de reprodução social dos agricultores familiares das comunidades rurais Custódia, Ribeirão, São Domingos e Tambiocó, no município de Catalão (G0). 
O município de Catalão localiza-se na região de planejamento Sudeste do estado de Goiás. A partir do estudo de Mendes (2005) e da pesquisa de campo foram identificadas 21 comunidades rurais em seu território: Pedra Branca, Olhos D’água, Matinha, Riacho, Tambiocó, Sucupira, Coqueiro, Macaúba, Morro Agudo, Cisterna, Ribeirão, Custódia, Mata Preta, Coruja, São Domingos, Pires, Olhos D’água, Anta Gorda, Contendas, Cruzeiro dos Martírios e Paulistas. 0 Mapa 1 se refere às comunidades rurais do município de Catalão (GO) e o Mapa 2 mostra as propriedades rurais visitadas e as respectivas comunidades pesquisadas.

$\mathrm{Na}$ pesquisa foram empregados os seguintes procedimentos metodológicos: a) pesquisa teórica; e b) pesquisa empírica. Concernente à pesquisa teórica, foram consultados Lamarche (1993), Bourdieu (1994 e 1996), Caume (2005), Tedesco (1999 e 2001), Wanderley (2001), Blum (2001), Schneider (2003), dentre outros.

Uma das principais técnicas empregadas na pesquisa foi a entrevista estruturada. Diante do exposto, nas comunidades rurais pesquisadas foi aplicado um formulário de entrevista a 75 responsáveis pela unidade produtiva, o que representou um percentual de 34,70\% das famílias, sendo 19 (35,18\%) na Custódia, 21 (35\%) na Ribeirão, 17 (33,33\%) na São Domingos e 18 (35,29\%) na Tambiocó, conforme se verifica na Tabela 1.

\begin{tabular}{l|c|c|c}
\hline \multicolumn{1}{c|}{ Comunidade } & Número de famílias & Formulários aplicados & Percentual \\
\hline Custódia & 54 & 19 & $35,18 \%$ \\
Ribeirão & 60 & 21 & $35,00 \%$ \\
São Domingos & 51 & 17 & $33,33 \%$ \\
Tambiocó & 51 & 18 & $35,29 \%$ \\
\hline Total & 216 & 75 & $34,70 \%$ \\
\hline
\end{tabular}

Tabela 1. Número de investigados (em \%): Comunidades Custódia, Ribeirão, São Domingos e Tambiocó no município de Catalão (GO). Fonte: Dados SIAB (2013) e pesquisa de campo (2013-2014). Org.: Silva (2014). 


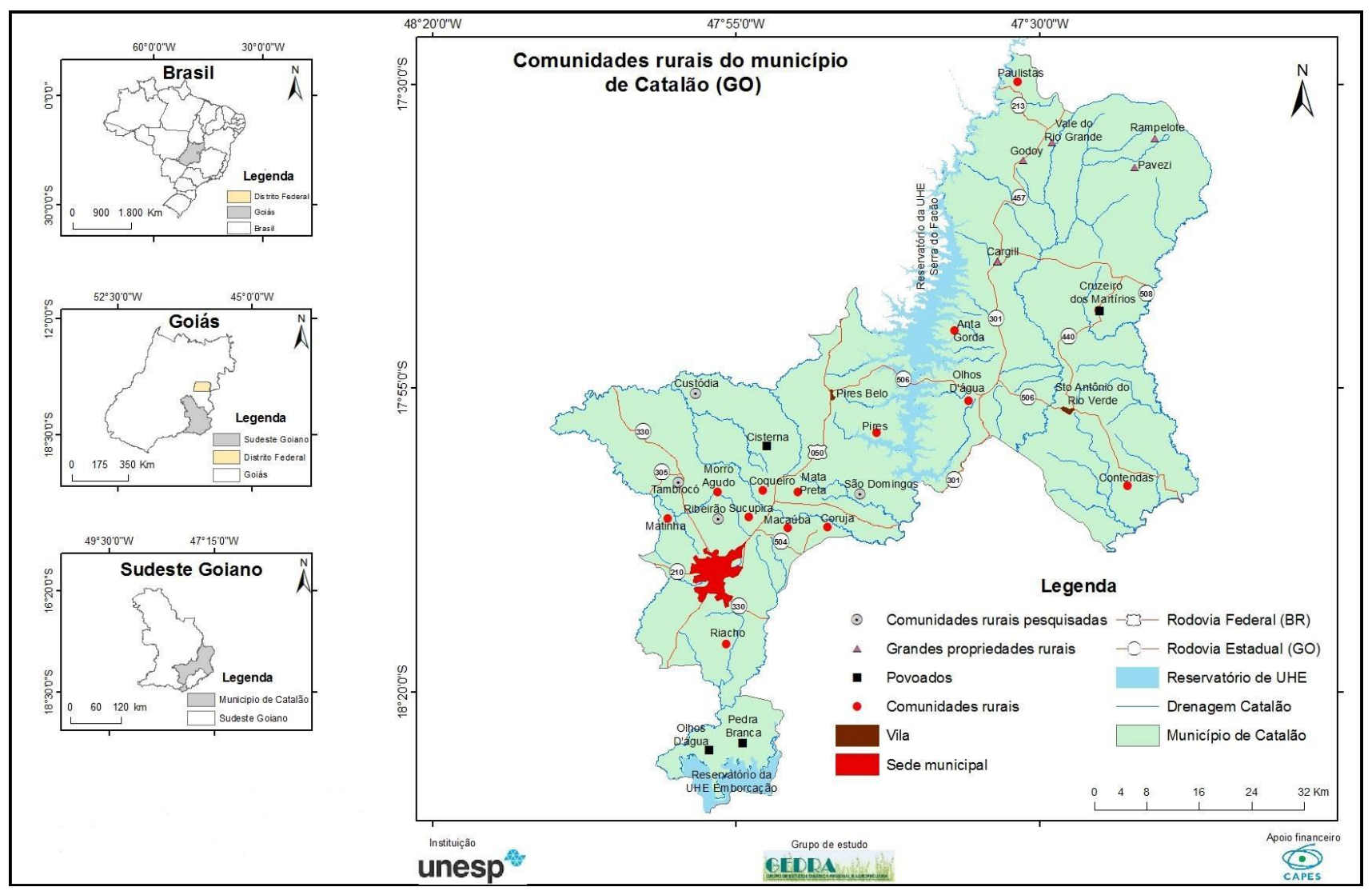

Mapa 1. Comunidades rurais do município de Catalão (GO) - 2015.

Fonte: Sistema Estadual de Geoinformação de Goiás (SIEG, 2015); Serra do Facão Energia S.A. (Sefac, 2015); Mendes (2005); e Rodrigues (2014). Org.: Rodrigues; Silva (2015). 


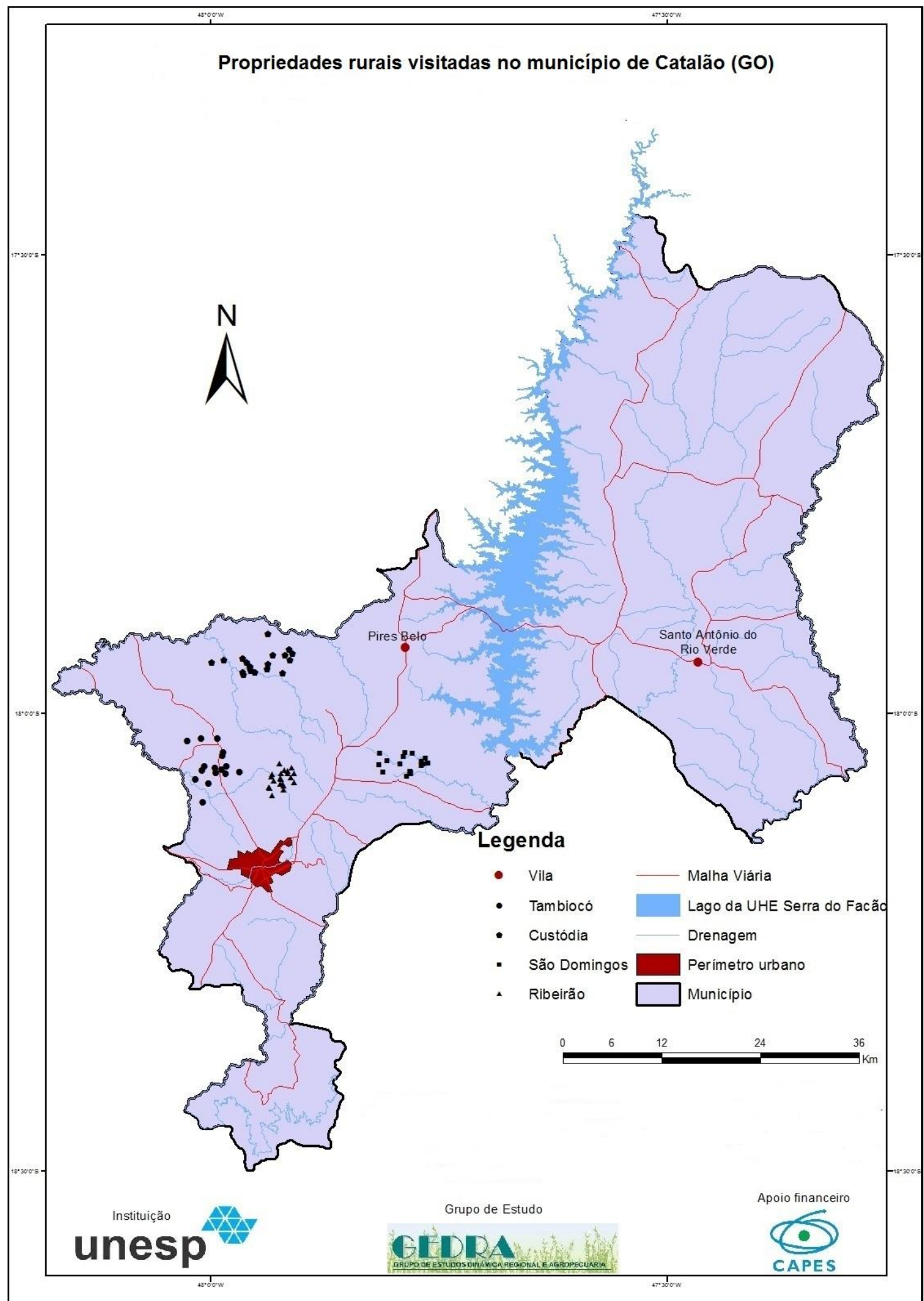

Mapa 2. Propriedades rurais visitadas: comunidades Custódia, São Domingos, Ribeirão e Tambiocó, município de Catalão (GO) - 2014. Fonte: Sistema Estadual de Geoinformação de Goiás (SIEG, 2015); Serra do Facão Energia S.A. (Sefac, 2015); e Pesquisa de campo (2013-2014). Org.: Rodrigues; Silva (2014). 
O texto está estruturado em duas (02) seções primárias, além desta introdução e das considerações finais. Sua organização procurou alcançar os objetivos que foram delineados. A primeira seção tem por fito compreender as discussões sobre estratégias de reprodução social, dando ênfase nas características da agricultura familiar no Brasil. Na segunda seção intitulada "Os agricultores familiares das comunidades rurais do município de Catalão e as estratégias adotadas" se discorreu sobre a diversificação produtiva, a participação no PNAE e nas feiras livres, dentre outras estratégias acionadas pelo grupo pesquisado.

\section{As estratégias de reprodução social dos agricultores familiares}

No Brasil, os agricultores familiares enfrentam diversos problemas tanto internos quanto externos à propriedade e à comunidade rural em que estão inseridos. De modo geral, os principais problemas enfrentados por esse segmento são: dificuldades na produção e comercialização; dificuldades de acesso às políticas públicas voltadas para o grupo; carência de maquinários e mão de obra; precarização dos acessos/estradas; inexistência de assistência médico hospitalar nas comunidades rurais; ausência de saneamento básico em suas localidades, dentre outros.

Assim sendo, os agricultores familiares têm acionado diversas estratégias como forma de garantir sua reprodução social, tais como: diversificação no cultivo de produtos e na criação de animais; e comercialização dos produtos agropecuários, viabilizada pelo Programa Nacional de Alimentação Escolar (PNAE), dentre outras.

A agricultura familiar não é uma categoria social recente no país, mas sua identificação como tal no Brasil tem propiciado diversas interpretações quanto ao seu significado nos últimos anos. No Brasil, os estudos utilizando a terminologia "agricultura familiar" tiveram maior ênfase a partir de meados da década de 1990, fato decorrente dos embates dos movimentos sociais acerca do papel desse segmento no processo de integração comercial e econômica do país e do desenvolvimento de trabalhos científicos nas diversas áreas como Economia, Sociologia, Geografia, dentre outras. Ressalta-se, ainda, o papel 
das políticas públicas na legitimidade do termo, principalmente, com a criação do Programa Nacional de Fortalecimento da Agricultura Familiar (PRONAF).

Sobre a definição e conceituação da agricultura familiar, a Lei n. 11.326, de 24 de julho de 2006, considera agricultor familiar aquele que pratica atividades no meio rural e atenda os seguintes requisitos: não detenha área maior que quatro (04) módulos fiscais, utilize predominantemente mão de obra familiar, tenha percentual mínimo da renda familiar originada de atividades do estabelecimento rural e dirija o estabelecimento com sua família.

Autores com Lamarche (1993) e Wanderley (2001) expõem que agricultura familiar corresponde a uma unidade de produção agrícola onde propriedade e trabalho estão ligados a família. Nesse sentido, a família é proprietária dos meios de produção e ao mesmo tempo assume o trabalho no estabelecimento. No entanto, pondera-se que essas características, tanto normativa quanto analítica, permitem dar sentido de particularidade e definir algumas tipologias, mas essa categoria apresenta uma diversidade de situações. Essa diversidade da agricultura familiar é condicionada por fatores naturais, sociais, econômicos e culturais.

Blum (2001), ao discutir a definição, a classificação e a problemática da agricultura familiar, enfatiza que as tendências da agricultura nos dias atuais estão inseridas num cenário de rápidas transformações e, muitas vezes, problemáticas em nível de mundo. Nesse sentido, a agricultura familiar tem acionado diversas estratégias que garante sua reprodução social.

No que tange às estratégias, Bourdieu (1994) expõe que podem ser divididas em cinco classes: a) estratégias de investimento biológico: são ligadas à fecundidade e as profiláticas - cuidado com o corpo; b) estratégias de sucessão: destinadas a garantir a transmissão de riqueza material entre as gerações com a menor perda possível dentro das oportunidades oferecidas pelo costume ou lei; c) estratégias educativas: envolvem o uso da educação e conhecimento formal (escolas) e a ética que determinam o comportamento da família; d) estratégias de investimento econômico: que estão 
dirigidas ao aumento de capital em suas diferentes espécies, que podem envolver relações sociais como as estratégias matrimoniais e a reprodução biológica; e) estratégias de investimento simbólico: envolvem o reconhecimento, as percepções, as aparências do grupo familiar, tencionando positivamente, perante as pessoas da sociedade.

Bourdieu (1996), ao tratar de estratégias, sendo essas direcionadas para as classes sociais ou segmentos da sociedade, afirma que a dinâmica social, marcada pela formação das condições de sobrevivência, produz estratégias de reprodução, ou seja, para ele a reprodução da ordem social ocorre, somente, através das estratégias. Para o autor, a estratégia é resultado da articulação de um senso prático e de um habitus ${ }^{2}$, no qual os indivíduos não constroem as estratégias como desejam, mas como condições cotidianas de sobrevivência, sejam sociocultural, econômica ou política.

Quanto às estratégias dos agricultores familiares, Tedesco (2001) e Wanderley (2001) ressaltam que os agricultores familiares vêm se adaptando às sociedades modernas devido a sua facilidade de adequação e as inúmeras estratégicas adotadas. Em relação à integração na agricultura moderna, Tedesco (2001) afirma que eles passaram a adotar diferentes tipos de estratégias para enfrentar os desafios. Para o autor:

[...] o agricultor familiar adota estratégias e aciona formas de racionalidades possíveis, enfrenta os desafios com as condições objetivas e os instrumentos que lhe são possíveis e ao seu alcance, dentre os quais a dimensão da historicidade que lhe é inerente e a incipiente participação nas políticas públicas. (TEDESCO, 2001, p. 13).

Assim, a agricultura familiar lança mão de várias estratégias. As estratégias podem ser definidas como um conjunto de ações racionais, em que cada membro da família tem a necessidade de assegurar, ao mesmo tempo, a própria reprodução, e a do grupo, tendo sempre a consciência dos mecanismos que

\footnotetext{
${ }^{2}$ Uma das funções da noção de habitus é dar conta da unidade de estilo que vincula as práticas e os bens de um agente singular ou de uma classe de agentes. $O$ habitus é o princípio gerador e unificador que retraduz as características intrínsecas e relacionais de uma posição de estilo de vida unívoco, isto é, em um conjunto unívoco de escolhas de pessoas, de bens e de práticas (BOURDIEU, 1996).
} 
podem proporcionar tais objetivos, como a tradição e a vinculação ao processo moderno de viver e produzir (LAMARCHE, 1998).

Schneider (2003) salienta que as estratégias são explicadas como o resultado das escolhas, opções e decisões dos indivíduos em relação à família e da família em relação aos indivíduos. É preciso ponderar que essas estratégias ocorrem nos limites de determinados condicionantes sociais, culturais, econômicos e até mesmo espaciais, que exercem pressões sobre as unidades familiares. Nessa perspectiva,

[...] a tomada de decisões e as opções, sejam quais forem, de indivíduos e famílias, possuem um referencial que na prática se materializa segundo as relações sociais, econômicas e culturais em que vivem. Assim, embora se tratem de estratégias conscientes e racionais, essa consciência é mediatizada por uma racionalidade informada pela realidade, que tanto é a expressão das relações materiais presentes, como daquelas herdadas de seu passado e transmitidas culturalmente. (SCHNEIDER, 2003, p. 172).

Nesse contexto, as estratégias não são causais, mas resultado da ação humana frente às contingências e situações objetivas. As estratégias de reprodução social são entendidas como elementos centrais para a compreensão das transformações na dinâmica da agricultura familiar, na qual os agricultores têm conseguido a permanência no campo. Schneider (2003) corrobora com a discussão ao afirmar que os mecanismos e as estratégias têm viabilizado e estimulado as formas familiares no campo.

A reprodução social é um processo dinâmico, isto é, dá-se por meio das transformações e adaptações ao longo do tempo. Acredita-se que, para compreender as estratégias de reprodução social dos agricultores é necessário entender as condições e as possibilidades de ação às quais este segmento tem enfrentado.

Para Sant'Ana (2003), as estratégias atendem a determinados projetos estabelecidos pelas famílias. O autor, ao estudar as estratégias dos produtores familiares de três municípios (Jaci, Valentim Gentil e Marinópolis), pertencentes à Mesorregião de São José do Rio Preto, expõe que as estratégias são processos, construções que nunca atingem uma forma definitiva, isto é, são fluídas. O projeto pode 
estar orientado para a manutenção da família na terra e criar as condições de sua reprodução social ligada à terra, mas as condições concretas podem engendrar estratégias que contrariam parcialmente esses projetos, pois foram avaliados como as mais adequadas ou as únicas possíveis naquele contexto. Todavia, não significa que o projeto tenha sido abandonado subjetivamente e que não possa ser retomado mais tarde.

As relações na agricultura se mostram como um processo dinâmico, portanto não estático, sofrendo diferentes influências, de acordo com cada peculiaridade. Essa multiplicidade e heterogeneidade constantes denotam diferentes formas e racionalidades vinculadas à propriedade e as experiências anteriores, bem como o contexto macro que dinamizam, em mais ou menos, na tomada de decisão por determinadas estratégias na sua unidade de produção, de acordo também a uma forma de gerir mais integrada ao mercado ou mais autônoma. Em outras palavras, cada realidade na agricultura familiar pode ser encarada de forma distinta, portanto, com estratégias diversas para conduzir sua reprodução social no meio rural (REDIN, 2011). Redin (2011) objetivou compreender e explicar os fatores que influenciam os agricultores familiares do município de Arroio do Tigre (RS) a optarem pela produção familiar fumageira como estratégia de reprodução social.

As estratégias dos agricultores devem ser pensadas a partir da relação com os aspectos políticos, econômicos e culturais. Assim, Alves (2004, p. 224), em estudo sobre a dinâmica agrária do munícipio de Ortigueira (PR) e reprodução social dos agricultores familiares das comunidades rurais de Pinhalzinho e Vila Rica, afirma que as estratégias estão diretamente ligadas ao modo de vida e as tradições desses sujeitos sociais, não somente como um reflexo das imposições estruturais da sociedade, tanto na esfera política, econômica, cultural e tecnológica, externos à unidade produtiva “[...] mas como ações desenvolvidas pela família na unidade de produção e nas relações de sociabilidade presentes no lugar e no seu cotidiano."

Verifica-se que, apesar das dificuldades enfrentadas pelos agricultores familiares das comunidades rurais, eles conseguem permanecer e reproduzir socialmente em virtude de uma série de estratégias. A seguir será abordado as características socioeconômicas, as estratégias que garantem a reprodução 
social, os principais impasses sociais e os problemas do segmento nas comunidades Custódia, Ribeirão,

São Domingos e Tambiocó, município de Catalão (G0).

\section{Os agricultores familiares das comunidades rurais do município de Catalão e as estratégias adotadas}

Nas comunidades rurais Custódia, Ribeirão, São Domingos e Tambiocó, notou-se que os agricultores familiares lançam diversas estratégias para garantir sua permanência e reprodução social no campo. A principal atividade econômica é a pecuária leiteira. No entanto, o segmento concilia a produção de leite com outras atividades como: diversificação na criação de animais e no cultivo de produtos, participação no PNAE, comercialização nas feiras, serviços temporários em atividades agropecuárias, dentre outros.

Nas comunidades rurais pesquisadas averiguou-se que o tamanho médio das propriedades rurais pesquisadas é de 47,34 ha. A área média das propriedades pesquisadas da comunidade Custódia é de 68,19 ha, na Ribeirão é de 28,65 ha, na São Domingos é de 43,23 ha e na Tambiocó é de 49,29 há (Tabela 2). Vale ressaltar que em Catalão (GO) o módulo fiscal é de 40 hectares.

\begin{tabular}{l|cccc|c}
\hline $\begin{array}{c}\text { Tamanho das } \\
\text { propriedades } \\
\text { (hectares) }\end{array}$ & Custódia & Ribeirão & São Domingos & Tambiocó & Frequência \\
\hline Até 10 ha & $10,53 \%$ & $38,09 \%$ & $17,65 \%$ & - & $16,57 \%$ \\
11 a 20 ha & $5,26 \%$ & $23,80 \%$ & $23,53 \%$ & $11,11 \%$ & $15,92 \%$ \\
21 a 30 ha & - & $9,53 \%$ & $17,65 \%$ & $27,78 \%$ & $13,74 \%$ \\
31 a 40 ha & $15,78 \%$ & $9,53 \%$ & $5,88 \%$ & $16,67 \%$ & $11,97 \%$ \\
41 a 50 ha & $10,53 \%$ & - & $5,88 \%$ & $22,23 \%$ & $9,66 \%$ \\
51 a 60 ha & $10,53 \%$ & $4,76 \%$ & $5,88 \%$ & $5,55 \%$ & $4,05 \%$ \\
61 a 70 ha & $10,53 \%$ & $9,53 \%$ & $5,88 \%$ & $5,55 \%$ & $4,02 \%$ \\
71 a 80 ha & $10,53 \%$ & $4,76 \%$ & $11,77 \%$ & - & $6,48 \%$ \\
81 a 90 ha & $10,53 \%$ & - & - & - & $6,77 \%$ \\
91 a 100 ha & $15,78 \%$ & - & $5,88 \%$ & $11,11 \%$ & $8,19 \%$ \\
\hline Acima de 100 ha & & - & - & - & $2,63 \%$ \\
\hline
\end{tabular}


Tabela 2. Frequência, em termos de área, das propriedades pesquisadas (em \%): comunidades Custódia, Ribeirão, São Domingos, Tambiocó, Catalão (GO) - 2013-2014. Fonte: Pesquisa de campo (2013-2014). Org.: Silva (2014).

Quanto à estrutura fundiária nota-se certa diferenciação de tamanho entre as unidades familiares das comunidades em estudo. Assim, deve-se considerar as condições naturais dos solos da região e a dificuldade de acesso as políticas públicas (federal, estadual e municipal) e assistência técnica especializada voltada para o segmento, explicando o fato que mesmo dispondo de maior quantidade de terras, os resultados econômicos alcançados mostram-se muitas vezes insuficientes à reprodução social das unidades produtivas e por que a terra é utilizada preferencialmente para a exploração da pecuária.

No que tange à renda monetária média mensal familiar averiguou-se que a maioria, ou seja, 73,21\% dos entrevistados possuem renda entre um (01) e três (03) salários mínimos. Já os que têm rendimento menor que um (01) salário mínimo representa, apenas, 1,2\%; entre três (03) e cinco (05) salários são 17,32\%; 6,96\% possuem rendimentos de cinco (05) a dez (10) salários mínimos; e apenas 1,31\% possui rendimento superior a dez (10) salários mínimos (Tabela 3). Vale considerar a oscilação dos rendimentos dessas famílias em função da instabilidade dos preços e de mercado para os produtos agrícolas. O valor do salário mínimo no momento da pesquisa de campo (julho de 2013 a março de 2014) era de $\mathrm{R} \$ 678,00$.

\begin{tabular}{l|cccc|c}
\hline \multicolumn{1}{c|}{ Renda mensal } & Custódia & Ribeirão & São Domingos & Tambiocó & Média \\
\hline Menos de 1 salário mínimo & - & $4,76 \%$ & - & - & $1,2 \%$ \\
entre 1 e 2 salários & $42,10 \%$ & $23,80 \%$ & $52,94 \%$ & $22,22 \%$ & $35,27 \%$ \\
entre 2 e 3 salários & $26,31 \%$ & $57,14 \%$ & $29,41 \%$ & $38,88 \%$ & $37,94 \%$ \\
entre 3 e 5 salários & $15,78 \%$ & $14,28 \%$ & $5,88 \%$ & $33,33 \%$ & $17,32 \%$ \\
entre 5 e 10 salários & $10,52 \%$ & - & $11,76 \%$ & $5,55 \%$ & $6,96 \%$ \\
Mais de 10 salários & $5,26 \%$ & - & - & - & $1,31 \%$ \\
\hline
\end{tabular}

Tabela 3. Renda monetária média mensal das famílias pesquisadas (em \%): comunidades Custódia, Ribeirão, São Domingos, Tambiocó, Catalão (GO) - 2013-2014. Fonte: Pesquisa de campo (2013-2014). Org.: Silva (2014). 
Uma das estratégias de reprodução social nas comunidades pesquisadas é a diversificação produtiva verificada pelas pesquisas de Lamarche (1993), Caume (2005), Mendes (2005), entre outros. Essa diversificação destina-se, não só a ampliar o leque de produtos comercializáveis, como também garantir o consumo familiar.

Conforme a Tabela 4, a principal atividade econômica dos agricultores familiares é a pecuária. Assim sendo, $86,44 \%$ das famílias visitadas criam bovinos. É expressiva, também, a criação de suínos $(68,15 \%)$ e galináceos $(93,23 \%)$, sendo essas destinadas, sobretudo, para o consumo familiar e equinos $(63,77 \%)$ para tração animal.

No que tange à finalidade da criação dos bovinos, a maioria $(70,42 \%)$ é destinada, principalmente, para a produção de leite. Caume (2005) salienta que a produção leiteira tende a se tornar uma estratégia produtiva dominante entre os produtores familiares de Goiás. Para o autor, esse processo está relacionado a um conjunto de fatores tanto estruturais quanto conjunturais como: a) dificuldade de ingresso competitivo no mercado da lavoura tecnificada de soja e milho; b) disponibilidade de terras de baixa qualidade; e c) expansão de agroindústrias processadoras de leite na região. Caume (2005) estudou a produção familiar no estado de Goiás, no qual considerou à heterogeneidade social, técnica e econômica presente nos municípios de Goiás (conhecido como Goiás Velho), Itapuranga, Formosa, Porangatu, Orizona e Rio Verde.

\begin{tabular}{l|cccc}
\hline Comunidades & Bovinos & Suínos & Equinos & Galináceos \\
\hline Custódia & $89,47 \%$ & $63,15 \%$ & $84,21 \%$ & $89,47 \%$ \\
Ribeirão & $85,71 \%$ & $66,66 \%$ & $57,14 \%$ & $95,23 \%$ \\
São Domingos & $70,58 \%$ & $70,58 \%$ & $47,05 \%$ & $88,23 \%$ \\
Tambiocó & $100,00 \%$ & $72,22 \%$ & $66,66 \%$ & $100,00 \%$ \\
\hline Média & $86,44 \%$ & $68,15 \%$ & $63,77 \%$ & $93,23 \%$ \\
\hline
\end{tabular}

Tabela 4. Informações sobre a pecuária de acordo com os agricultores pesquisados (em \%): comunidades Custódia, Ribeirão, São Domingos e Tambiocó, Catalão (GO) - 2013-2014. Fonte: Pesquisa de campo (20132014). Org.: Silva (2014). 
Nas propriedades rurais pesquisadas, a média da produção de leite, é de 73,05 litros/dia por produtor, porém existe uma grande variação entre eles, que oscila de 10 a 300 litros por dia. Todavia, a produção de leite é conciliada com a cria/recria e com o corte (Tabela 5).

\begin{tabular}{l|ccc}
\hline Comunidades & Leite & Cria/Recria & Corte \\
\hline Custódia & $70,59 \%$ & $17,64 \%$ & $11,77 \%$ \\
Ribeirão & $83,33 \%$ & $5,56 \%$ & $11,11 \%$ \\
São Domingos & $66,67 \%$ & $8,33 \%$ & $25 \%$ \\
Tambiocó & $61,10 \%$ & $5,56 \%$ & $33,34 \%$ \\
\hline Média & $70,42 \%$ & $9,27 \%$ & $20,31 \%$ \\
\hline
\end{tabular}

Tabela 5. Finalidade principal da bovinocultura de acordo com os agricultores pesquisados (em \%): comunidades Custódia, Ribeirão, São Domingos e Tambiocó, Catalão (GO) - 2013-2014. Fonte: Pesquisa de campo (20132014). Org.: Silva (2014).

De modo geral, o leite é ordenhado manualmente, sendo que apenas $10,18 \%$ dos investigados afirmaram utilizar ordenha mecânica. Das famílias que produzem leite, 51,74\% optam pela comercialização do leite in natura, sendo entregue para a Cooperativa Agropecuária de Catalão LTDA (COACAL). A COACAL é a responsável pelo recolhimento do leite. No entanto, 67,26\% dos pesquisados afirmaram entregar o leite resfriado, sendo feito em tanques com capacidade que variam de 250 a 1.500 litros. Em 2013-2014, o preço médio do litro de leite variava entre $\mathrm{R} \$ 0,60$ e $\mathrm{R} \$$ 1,00, essa variação de preço é decorrente da quantidade de leite entregue e da condição de entrega, isto é, o resfriamento do leite agrega valor ao produto. Cumpre lembrar que durante o período de seca (maio a setembro), o leite e seus derivados têm preço melhor, porém com a diminuição nutricional das pastagens, o custo com a manutenção do rebanho aumenta, pois os animais devem ser suplementados com silagem, proteína de soja, dentre outros.

Já 34,93\% das famílias preferem produzir queijos, sendo que o preço médio do quilo é em torno de $\mathrm{R} \$$ 10,00. Esses queijos são comercializados em mercearia, panificadoras, feiras e diretamente ao 
consumidor. Verificou-se que, a produção de queijo nessas comunidades rurais não possui certificação de qualidade, o que dificulta a comercialização e a agregação de valor. Cabe mencionar que os produtores de queijo aproveitam o soro, resultante da fabricação de queijo, para a alimentação de suínos.

Outros 7,5\% das famílias afirmaram utilizar o leite, sobretudo, para o consumo familiar, sendo consumido líquido e por meio de queijos, doces, bolos, requeijão, dentre outros. Cabe mencionar que, os criadores de pecuária leiteira demonstraram insatisfação com o preço dos produtos (queijo e leite), sendo que grande parte dos rendimentos são investidos para a prevenção de doenças (vacinação e combate a parasitas), manutenção do rebanho (manutenção de pastos e suplementação alimentar), dentre outros.

Outros produtos derivados do leite refere-se ao requeijão de corte (Figura 1 e 2) e aos doces. A produção de requeijão não é comum entre as famílias entrevistadas, sendo poucas as que produzem $(2,70 \%)$, devido à dificuldade em sua preparação. Constatou-se que uma (01) família na comunidade Tambiocó produz requeijão e comercializa informalmente na cidade de Catalão, arrecadando, aproximadamente, $R \$ 500,00$ por mês, sendo esse montante importante para a complementação da renda familiar.

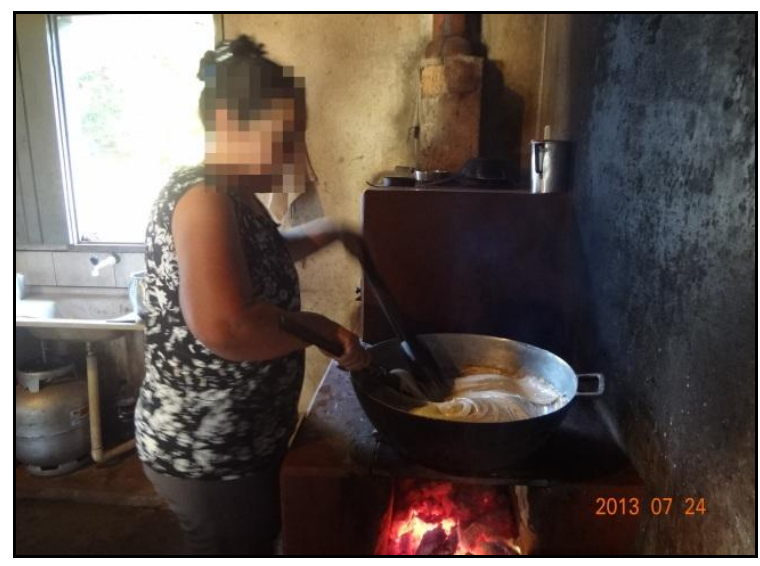

Figura 1. Produção de requeijão, Tambiocó, Catalão (GO) - 2013. Fonte: Pesquisa de campo (jul. 2013). Autora: Silva.

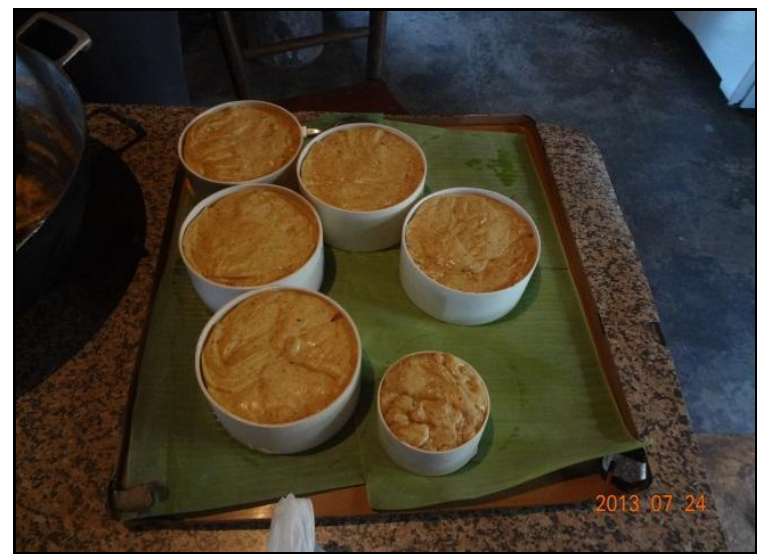

Figura 2. 0 requeijão pronto e nas formas, Tambiocó, Catalão (GO) - 2013. Fonte: Pesquisa de campo (jul. 2013). Autora: Silva. 
Alusivo às outras criações mencionadas na Tabela 4, 68,15\% das famílias criam suínos, 63,77\% equinos e 93,23\% galináceos. Essas criações são destinadas, sobretudo, para o consumo familiar, com o intuito de atender as necessidades alimentares da família, mas, de modo geral, o excedente é comercializado.

Quantos aos suínos, apenas três (03) agricultores, o que representa 5,45\%, criam suínos, principalmente para a comercialização, sendo um (01) em cada comunidade (Custódia, Ribeirão e Tambiocó). Esses agricultores comercializam, em média, 15 suínos por ano e arrecadam, em média, R\$ 2.500,00, sendo que o preço de cada suíno varia entre $R \$ 100,00$ e 300,00. Os equinos são utilizados, basicamente, como força animal para os afazeres no campo, sendo que $63,76 \%$ das propriedades rurais possuem de uma (01) a duas (02) cabeças de equinos.

A criação de galináceos nas propriedades rurais pesquisadas oscila de 20 a 300 cabeças. Apenas 10\% dos produtores criam galináceos, principalmente, para a comercialização, no qual $5 \%$ são comercializados por meio de intermediários e $5 \%$ são vendidos diretamente pelas famílias nas feiras da cidade de Catalão, sendo que o preço médio é em torno de $\mathrm{R} \$ 20,00$. Os galináceos são criados em sistema caipira e são destinados, principalmente, para a produção de carne e ovos.

É evidenciada, ainda, a diversificação de lavouras nas comunidades Custódia, Ribeirão, São Domingos e Tambiocó. A maior parte dos pesquisados cultivam milho (78,53\%), cana-de-açúcar (23,21\%), mandioca $(75,90 \%)$, frutas $(90,41 \%)$ e hortaliças $(86,63 \%)$, conforme se verifica na Tabela 6 .

Verificou-se que nessas comunidades rurais existem outros tipos de lavouras, sendo essas destinadas para a comercialização. Na comunidade rural Ribeirão 9,52\% cultivam eucaliptos e 9,52\% tomate; na São Domingos 5,88\% produzem feijão e 5,88\% soja; e na Tambiocó 5,55\% produzem tomate. Vale destacar que 5,88\% na comunidade São Domingos e 9,52\% na Ribeirão arrendam parcela de suas terras para o cultivo de grãos. 


\begin{tabular}{l|cccccc}
\hline \multirow{2}{*}{ Comunidade } & \multicolumn{5}{|c}{ Principais lavouras } \\
\cline { 2 - 7 } & Milho & $\begin{array}{c}\text { Cana-de- } \\
\text { açúcar }\end{array}$ & Mandioca & Frutas & Hortaliças & Outros \\
\hline Custódia & $78,94 \%$ & $21,05 \%$ & $68,42 \%$ & $84,21 \%$ & $78,94 \%$ & - \\
Ribeirão & $80,95 \%$ & $14,28 \%$ & $80,95 \%$ & $100,00 \%$ & $90,47 \%$ & $19,04 \%$ \\
São Domingos & $76,47 \%$ & $35,29 \%$ & $76,47 \%$ & $94,11 \%$ & $88,23 \%$ & $11,76 \%$ \\
Tambiocó & $77,77 \%$ & $22,22 \%$ & $77,77 \%$ & $83,33 \%$ & $88,88 \%$ & $5,55 \%$ \\
\hline Média & $78,53 \%$ & $23,21 \%$ & $75,90 \%$ & $90,41 \%$ & $86,63 \%$ & $9,08 \%$ \\
\hline
\end{tabular}

Tabela 6. Principais lavouras (em \%) pelos agricultores pesquisados: comunidades Custódia, Ribeirão, São Domingos e Tambiocó, Catalão (GO) - 2013-2014. Fonte: Pesquisa de campo (2013-2014). Org.: Silva (2014).

Algumas dessas lavouras são destinadas, especialmente, para o consumo familiar. O milho é aproveitado sob diferentes formas, sendo usado em: a) silagem para a suplementação dos bovinos e b) espigas, grãos e farelo para a alimentação dos animais (gado, suínos e galináceos). Todavia, 30,76\% dos entrevistados da comunidade São Domingos comercializam milho.

O milho também é utilizado na dieta alimentar, sendo comum na preparação de pratos como pamonha (Figuras 3 e 4), angu, curau, dentre outros. A prática da produção das pamonhas é um momento importante de sociabilidade, pois reúne os familiares e os vizinhos para o seu preparo.

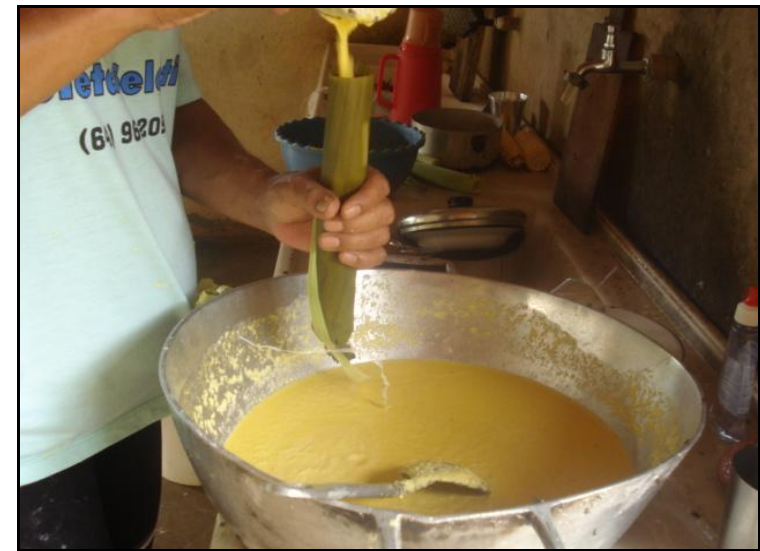

Figura 3 - Produção de pamonhas: comunidade Ribeirão, Catalão (G0) - 2013. Fonte: Pesquisa de campo (ago. 2013). Autora: Silva.

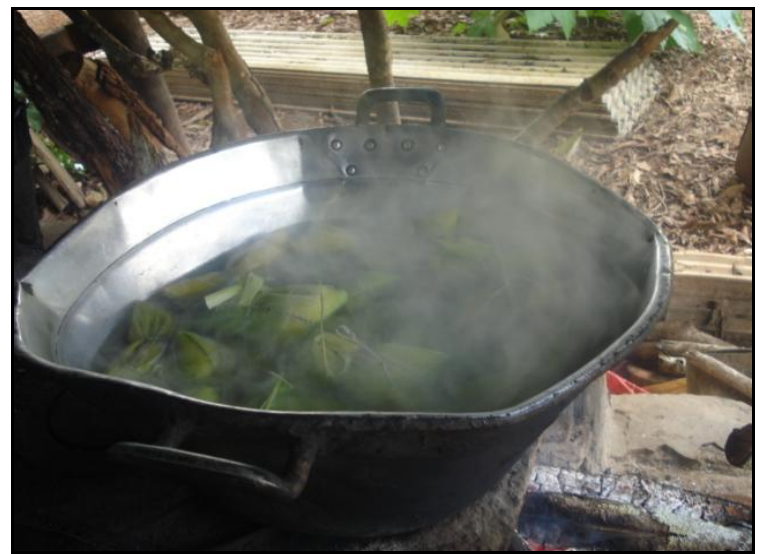

Figura 4 - Produção de pamonhas: comunidade Ribeirão, Catalão (GO) - 2013. Fonte: Pesquisa de campo (ago. 2013). Autora: Silva. 
A cana-de-açúcar é, basicamente, empregada no trato dos bovinos. Apenas uma (01) família na comunidade Ribeirão faz cachaça, açúcar mascavo e rapadura e uma (01) na comunidade Tambiocó faz rapadura. A renda mensal com essas produções gira em torno de $R \$ 200,00$ à $R \$ 500,00$ mensais, se constituindo em uma importante estratégia de reprodução social.

A produção de mandioca é usada, sobretudo, para fazer farinha de mandioca e polvilho. Grande parte da produção é voltada para o consumo familiar e o excedente é comercializado informalmente para vizinhos, mercearias e feiras livres. A renda adquirida com o excedente da produção se constitui num importante complemento na renda das famílias. Nas comunidades pesquisadas, $41,45 \%$ das famílias produzem farinha de mandioca e 38,75\% polvilho, conforme se verifica na Tabela 7 .

Verificou-se que, apenas, duas famílias cultivam mandioca, especialmente, para a comercialização. Dessas famílias, uma (01) reside na comunidade São Domingos, produz cerca de 2.000 toneladas de mandioca por ano e arrecada $\mathrm{R} \$ 6.000,00$ por ano. A outra família mora na comunidade Ribeirão e 0 agricultor produz cerca de 2.500 toneladas e arrecada, aproximadamente, $\mathrm{R} \$ 7.000,00$. Em ambos os casos, a mandioca é vendida descascada e a comercialização é realizada por meio de intermediários.

\begin{tabular}{l|cc}
\hline \multicolumn{1}{c|}{ Comunidades } & $\begin{array}{c}\text { Farinha de } \\
\text { mandioca }\end{array}$ & Polvilho \\
\hline Custódia & $47,36 \%$ & $42,10 \%$ \\
Ribeirão & $38,09 \%$ & $38,09 \%$ \\
São Domingos & $47,05 \%$ & $47,05 \%$ \\
Tambiocó & $33,33 \%$ & $27,77 \%$ \\
\hline Média & $41,45 \%$ & $38,75 \%$ \\
\hline
\end{tabular}

Tabela 7. Produção de farinha de mandioca e polvilho (em \%) dos agricultores pesquisados: comunidades Custódia, Ribeirão, São Domingos e Tambiocó, Catalão (GO) - 2013-2014. Fonte: Pesquisa de campo (20132014). Org.: Silva (2014). 
É comum a produção de verduras e legumes, sendo que 86,63\% dos agricultores familiares produzem, sendo geralmente cultivados nas hortas. As verduras e os legumes mais cultivados nessas comunidades são: alface, couve, jiló, chuchu, abóbora, pimenta e cebola, sendo empregadas no consumo familiar e comercializadas em feiras livres e entregues para o PNAE. As famílias, ainda, cultivam plantas medicinais, sendo usadas para combater resfriados, gripes, dores, dentre outros (Tabela 8)

\begin{tabular}{|c|c|c|c|c|c|}
\hline $\begin{array}{c}\text { Verduras e } \\
\text { legumes }\end{array}$ & Custódia & Ribeirão & $\begin{array}{c}\text { São } \\
\text { Domingos }\end{array}$ & Tambiocó & Média \\
\hline Alface, couve & 68,42 & 66,66 & 64,70 & 77,77 & 69,38 \\
\hline Cebola, alho & 31,57 & - & 11,76 & 22,22 & 21,85 \\
\hline $\begin{array}{l}\text { Cenoura, } \\
\text { beterraba }\end{array}$ & 31,57 & 23,80 & 23,52 & 16,66 & 23,88 \\
\hline Repolho & 52,63 & 47,61 & 64,70 & 38,88 & 50,95 \\
\hline $\begin{array}{l}\text { Especiarias } \\
\text { (temperos, } \\
\text { pimenta) }\end{array}$ & 68,42 & 42,85 & 64,70 & 83,33 & 64,82 \\
\hline Pepino, jiló & 26,31 & 23,80 & 29,41 & 44,44 & 30,99 \\
\hline Chuchu & 52,63 & 42,85 & 58,82 & 72,22 & 56,63 \\
\hline Abóbora & 78,94 & 33,33 & 47,05 & 50 & 52,33 \\
\hline Pimenta & 31,57 & 38,09 & 35,29 & 66,66 & 42,90 \\
\hline $\begin{array}{l}\text { Plantas } \\
\text { medicinais }\end{array}$ & 42,10 & 33,33 & 41,17 & 66,66 & 45,81 \\
\hline Outros & 5,26 & 14,28 & 11,76 & 16,66 & 11,99 \\
\hline
\end{tabular}

Tabela 8. Produção de verduras e legumes (em \%): comunidades Custódia, Ribeirão, São Domingos, Tambiocó, Catalão (GO) - 2013-2014. Fonte: Pesquisa de campo (2013-2014). Org.: Silva (2015).

A maioria $(90,41 \%)$ das famílias produz frutíferas, sendo destinadas, sobretudo, ao consumo familiar. Grande parte das residências visitadas possuem pomares e as principais árvores frutíferas presentes são: laranjeira e limoeiro, goiabeira, abacateiro, mamoeiro, mangueira, bananeira, pequizeiro (Caryocar brasiliense) e outras (aceroleira, maracujazeiro, figueira, cajueiro, romãzeira e jabuticabeira) (Tabela 9).

\begin{tabular}{l|cccc|c}
\hline \multicolumn{1}{c|}{ Frutíferas } & Custódia & Ribeirão & São Domingos & Tambiocó & Média \\
\hline $\begin{array}{l}\text { Laranjeira } \\
\text { limoeiro }\end{array}$ & 94,73 & 90,47 & 82,35 & 83,33 & 87,72
\end{tabular}




\begin{tabular}{l|llll|l} 
Goiabeira & 78,94 & 61,90 & 76,47 & 88,88 & 76,54 \\
Abacateiro & 78,94 & 52,38 & 82,35 & 66,66 & 70,08 \\
Mamoeiro & 73,68 & 66,66 & 82,35 & 72,22 & 73,72 \\
Mangueira & 94,73 & 85,71 & 76,47 & 88,88 & 86,44 \\
Bananeira & 78,94 & 71,45 & 76,47 & 83,33 & 77,54 \\
Pequizeiro & 36,84 & 23,80 & 17,64 & 55,55 & 33,45 \\
Outras & 47,36 & 38,09 & 52,94 & 55,55 & 48,48
\end{tabular}

Tabela 9. Produção de frutas (em \%): comunidades Custódia, Ribeirão, São Domingos, Tambiocó, Catalão (GO) - 2013-2014. Fonte: Pesquisa de campo (2013-2014). Org.: Silva (2015).

No que tange à comercialização de frutas, constatou-se que: a) na comunidade São Domingos, um (01) agricultor produz maracujá; b) na Tambiocó, um (01) produz laranja e maracujá, que são entregues no PNAE e comercializadas na feira; c) na comunidade Ribeirão, um (01) produz banana, limão e maracujá, que são comercializados nas feiras da Praça Duque de Caxias, da Prefeitura e da Vila União da cidade de Catalão e um (01) agricultor plantou 3.000 pés de diversas frutas, que está em fase de crescimento, com o intuito de comercializar a produção.

É comum nessas comunidades a produção de doces. A maioria das famílias produz para o consumo familiar, mas 6,66\% comercializam nas feiras livres da cidade de Catalão (GO). Os principais doces feitos são: de leite, mamão e figo. Nas Figuras 5 e 6 é possível visualizar o preparo dos doces de figo e mamão.

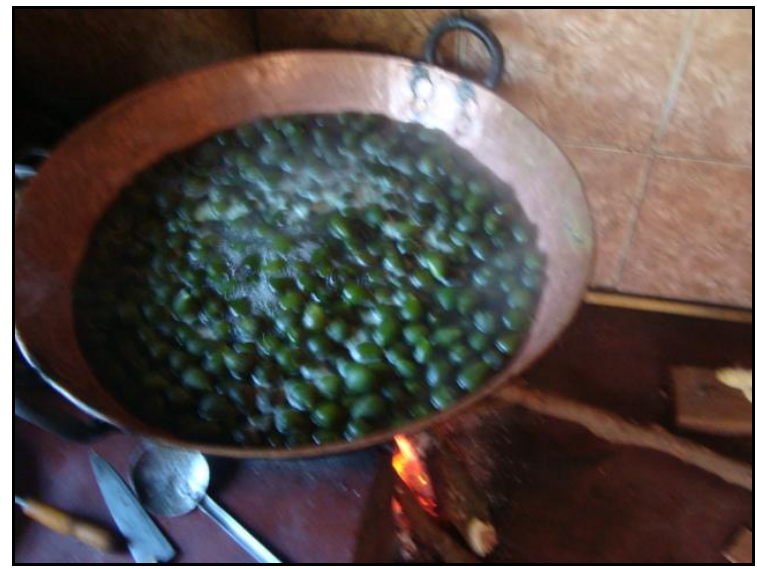

Figura 5 - Produção de doce de figo para consumo familiar: comunidade Custódia, Catalão

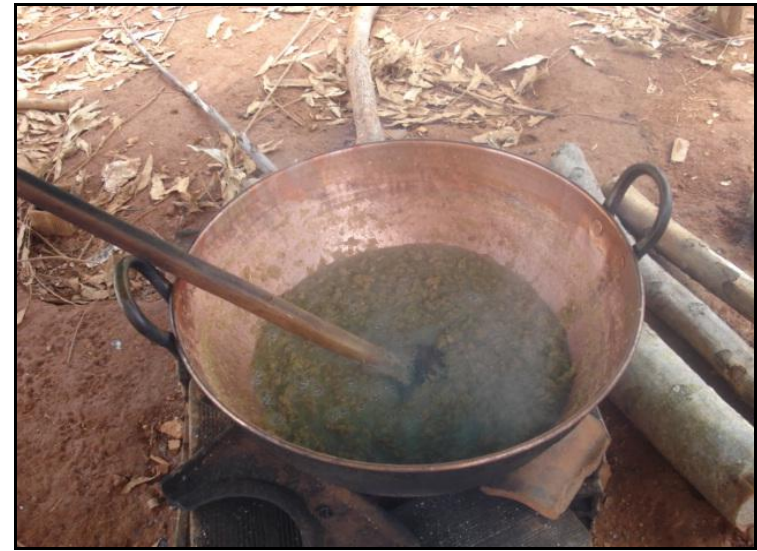

Figura 6 - Produção de doce de mamão para comercialização na feira: comunidade Ribeirão, Catalão (GO) - 2013. Fonte: Pesquisa de campo 
(GO) - 2014. Fonte: Pesquisa de campo (mar. (ago. 2013). Autora: Silva. 2014). Autora: Silva.

Apesar da comercialização de parcela da produção agropecuária, o consumo familiar é uma estratégia recorrente entre os agricultores familiares, sendo fundamental para a reprodução social destas unidades. Gazolla e Schneider (2007), Grisa e Schneider (2008) e Grisa, Gazolla e Schneider (2010) expõem que o 'autoconsumo' ou consumo familiar é, popularmente, denominado produção "pro gasto", constitui todo o tipo de produção, bens, ferramentas de trabalho ou outros produtos que são gerados no interior da unidade familiar e utilizados pelos seus membros para suprir as suas necessidades.

Nas comunidades rurais pesquisadas, o 'autoconsumo' alimentar refere-se a parcela da criação de animal (bovinos, suínos, galináceos, etc.), produção vegetal (lavouras, hortas e pomar) e fabricação caseira (farinha de mandioca, polvilho, queijo, requeijão, doces e quitandas ${ }^{3}$ ) que é realizada pelos membros da família e que é utilizada na alimentação do grupo doméstico de acordo com as suas necessidades.

Gazolla e Schneider (2007) destacam que o 'autoconsumo' também é importante por ser um "instrumento" de sociabilização das famílias e comunidades rurais, pois é por meio da sua produção que muitas famílias se aproximam, nas relações sociais e trocas destinadas à alimentação, ao plantio e à criação animal, tornando-a uma produção para 'autoconsumo' criadora de vínculos morais e afetivos entre famílias e indivíduos.

Grisa e Schneider (2008) salientam que embora a produção para o consumo familiar atenda em grande medida as necessidades alimentares, há alimentos que não podem ser produzidos pela família e que são indispensáveis. O atendimento destas e outras necessidades demanda que a família estabeleça relações com os mercados através a comercialização de parte da produção.

${ }^{3}$ Quitandas são pães, biscoitos, bolos e doces. 
Deste modo, o excedente da produção agropecuária é comercializada nas feiras livres. Nas comunidades rurais Ribeirão, São Domingos e Tambiocó, 9,29\% dos agricultores familiares participam de feiras livres realizadas na cidade de Catalão (GO). As feiras são organizadas pelas famílias e constituem uma relevante estratégia de reprodução social, pois é um meio de comercialização e valorização de seus produtos.

Os agricultores familiares do município de Catalão (G0), de modo geral, têm procurado diversificar sua produção e comercializar diretamente parte da mesma como estratégia de assegurar os rendimentos necessários para garantir sua reprodução social. As feiras livres existentes no município viabilizam esse mecanismo. Para Mendes (2005, p. 250), "a feira é uma oportunidade para os produtores comercializarem, diretamente, seus produtos, aumentando a possibilidade de agregar valores. Vários produtores vêem na feira um meio de complementar sua renda [...]."

Guimarães (2010), ao abordar a importância das propostas dos movimentos sociais para a resistência política, econômica e cultural dos camponeses da comunidade Ribeirão, no município de Catalão (GO), a partir da leitura do território e do lugar, expõe que a feira é um espaço de venda direta ao consumidor e importante instrumento para as famílias comercializarem seus produtos diretamente ao consumidor, eliminando, assim, o intermediário. Guimarães (2010) pontua que o acesso ao mercado é um desafio a ser enfrentado pelo segmento de pequenos produtores. Porém, as feiras livres se constituem numa estratégia que vem se firmando com sucesso.

Das famílias pesquisadas, $14,28 \%$ na comunidade Ribeirão, 11,76\% na São Domingos e 11,11\% na Tambiocó participam das feiras, principalmente, da feira camponesa no Bairro Ipanema (organizada pelo Movimento Camponês Popular (MCP), conforme se verifica na Tabela 10.

Nas feiras livres são comercializadas verduras, legumes, frutas, frangos caipira e produtos oriundos da produção caseira, como farinha de mandioca, polvilho, queijos, requeijão, doces, rapadura, dentre 
outros. Alguns agricultores comercializam, ainda, salgados (coxinhas, pasteis, quibes etc.), caldos e sucos.

\begin{tabular}{l|c|c}
\hline \multicolumn{1}{c|}{ Comunidade } & $\begin{array}{c}\text { N. de famílias } \\
\text { participantes }\end{array}$ & Participação em feiras \\
\hline Custódia & - & - \\
Ribeirão & 03 & $14,28 \%$ \\
São Domingos & 02 & $11,78 \%$ \\
Tambiocó & 02 & $11,11 \%$ \\
\hline Total & 07 & $9,29 \%$ \\
\hline
\end{tabular}

Tabela 10. Participação das famílias pesquisadas nas feiras livres: Catalão (GO) (em \%) - 2013-2014. Fonte: Pesquisa de campo (2013-2014). Org.: Silva (2014).

As principais feiras livres na cidade de Catalão, que contam com a participação dos agricultores familiares pesquisados, acontecem nos seguintes locais: no Bairro Ipanema; na praça Duque de Caxias; em frente à Prefeitura Municipal de Catalão; e no Bairro Vila Mutirão. As fotos 7 e 8 se referem a Feira dos Camponeses realizada no Bairro Ipanema. Essa feira foi criada em 2009, sendo organizada pelas famílias vinculadas ao Movimento Camponês Popular (MCP).

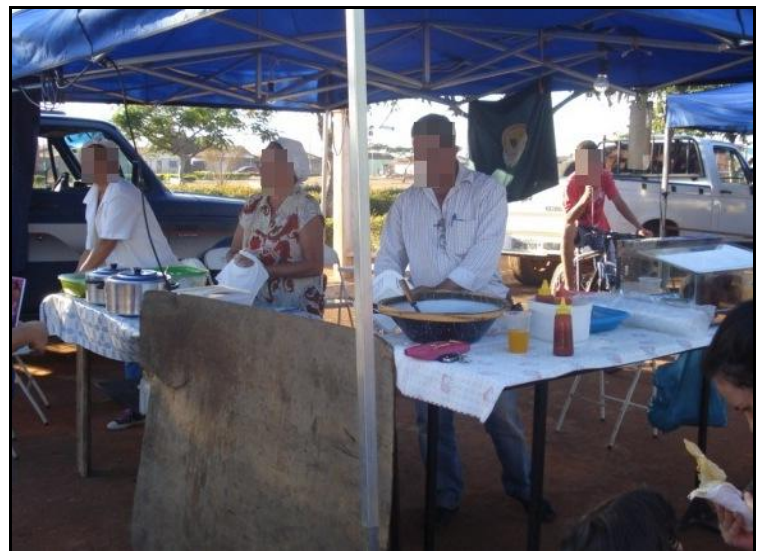

Foto 7 - Feira no Bairro Ipanema, Catalão (GO) 2013. Fonte: Pesquisa de campo (ago. 2013). Autora: Silva.

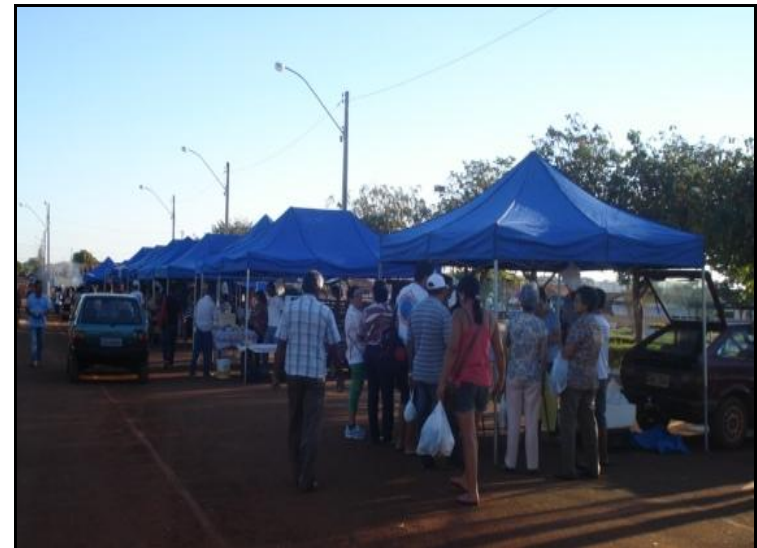

Foto 8 - Feira no Bairro Ipanema, Catalão (GO) - 2013. Fonte: Pesquisa de campo (ago. 2013). Autora: Silva. 
A comercialização dos produtos agropecuários, também, é viabilizada pelo Programa Nacional de Alimentação Escolar (PNAE). De acordo com o representante do MCP de Catalão, W. A. Ferreira (informação verbal, comunidade São Domingos, dez. 2013), os participantes do PNAE são residentes das comunidades rurais Macaúba, Coqueiros, São Domingos, Ribeirão, Cruzeiro dos Martírios e Mata Preta. Nas comunidades estudadas, constatou-se que, 17,64\% dos entrevistados da comunidade São Domingos, 11,11\% na Tambiocó e 14,28\% na Ribeirão participam do PNAE (Tabela 11). Na comunidade Custódia nenhum dos pesquisados participam do programa, sendo que um dos motivos é a distância (cerca de $40 \mathrm{~km}$ da cidade de Catalão), onde são entregues os produtos, enquanto as comunidades São Domingos, Ribeirão e Tambiocó localizam-se entre 10 e 15 km.

\begin{tabular}{l|c|c}
\hline \multicolumn{1}{c|}{ Comunidade } & $\begin{array}{c}\text { N. de famílias } \\
\text { participantes }\end{array}$ & $\begin{array}{c}\text { Participação no PNAE } \\
\text { em \% }\end{array}$ \\
\hline Custódia & - & - \\
Ribeirão & 03 & $14,28 \%$ \\
São Domingos & 03 & $17,64 \%$ \\
Tambiocó & 02 & $11,11 \%$ \\
\hline Total & 08 & $10,75 \%$ \\
\hline
\end{tabular}

Tabela 11. Participação dos agricultores pesquisados no Programa Nacional de Alimentação Escolar (PNAE) (em \%) - 2013-2014. Fonte: Pesquisa de campo (2013-2014). Org.: Silva (2014).

O representante do MCP de Catalão e participante do PNAE, W. A. Ferreira (informação verbal, comunidade São Domingos, dez. 2013) salienta, ainda, que o PNAE colabora para a desconcentração da renda. Assim, a mulher e os filhos passam a participar não só da produção, mas nos rendimentos, o que pode contribuir para a permanência dos jovens no meio rural.

A partir dos relatos dos agricultores familiares que participam do PNAE, verificou-se que o programa possui importância para a comercialização e a geração de renda e, consequentemente, a reprodução social dos agricultores familiares. No entanto, salienta-se que o programa atende uma pequena parcela, isto é, 59 agricultores familiares do município. Deve-se ponderar que alguns agricultores familiares por não terem interesse em participar do MCP, acabam não participando do programa no município. 
Referente ao Pronaf, 36,25\% dos pesquisados afirmaram recorrer à financiamentos e/ou empréstimos, sendo que destes: 96,87\% informaram que são provenientes do Pronaf. O Pronaf também contribui para o desenvolvimento da produção agropecuária.

Nas comunidades rurais pesquisadas, se verificou que o trabalho familiar se constituiu numa importante estratégia de reprodução social. De modo geral, os homens são os principais responsáveis pelas lavouras e a criação dos animais. Todavia, as mulheres desempenham um papel fundamental no trabalho relacionado as lavouras e a criação de animais.

Averiguou-se que nas comunidades rurais pesquisadas, as mulheres agricultoras são as principais responsáveis pelas atividades de manutenção do núcleo familiar. São encarregadas, ainda, pela produção caseira de farinha de mandioca, polvilho, pamonhas, queijos, requeijão, doces e quitandas, destinada ao consumo familiar e à comercialização. Salienta-se a relevância das mulheres na produção e, consequentemente, na comercializada dos produtos agropecuários nas feiras livres e no Programa Nacional de Alimentação Escolar (PNAE).

Apesar da importância do trabalho feminino nas unidades familiares, autores como Carneiro (2001), Brumer (2004), Garcia (2004) e Boni (2005) expõem que as atividades agropecuárias desenvolvidas pelas mulheres são consideradas como "ajuda". Nessa perspectiva, chamam atenção para a ‘invisibilidade' do papel das mulheres na agricultura familiar.

Constatou-se que nas comunidades rurais pesquisadas, a diversificação produtiva de animais e lavouras é uma importante estratégia de reprodução social, pois além de ser destinada para o consumo familiar, contribui para a melhoria dos rendimentos das famílias de agricultores familiares nas comunidades rurais do município de Catalão (GO), o que favorece a permanência do segmento no meio rural. Salienta-se, ainda, a relevância da comercialização dos produtos agropecuários nas feiras livres realizadas na cidade de Catalão (GO). 


\section{CONSIDERAÇÕES FINAIS}

De modo geral, os agricultores familiares acionam diversas estratégias que têm viabilizado a reprodução social e a permanência do grupo no meio rural. Entende-se que as estratégias são definidas como um conjunto de ações racionais, resultantes de escolhas, opções e decisões dos indivíduos. Salienta-se, também, que essas estratégias devem ser pensadas de acordo com as particularidades de cada localidade, ou seja, deve se considerar os aspectos políticos, econômicos e culturais (TEDESCO, 2001; WANDERLEY, 2001; SCHNEIDER, 2003; SANT'ANA, 2003; ALVES, 2004).

No que tange às comunidades rurais Custódia, Ribeirão, São Domingos e Tambiocó, os agricultores familiares possuem propriedades rurais com tamanho médio de 47,34ha. A maioria (73,19\%) dos pesquisados declarou ter renda entre 1 e 3 salários mínimos, no qual 85,7\% afirmaram que a fonte de renda principal é proveniente das atividades agropecuárias exercidas nas propriedades rurais que residem.

Uma das estratégias acionadas pelos pesquisados é a diversificação produtiva, que combina a criação de animais com o cultivo de lavouras. Alusivo à criação de animais, 86,44\% das famílias visitadas criam bovinos, 68,15\% têm suínos e 93,23\% possuem galináceos. E concernente ao cultivo de lavouras, 78,53\% cultivam milho, 23,21\% cana-de-açúcar e 75,90\% mandioca, além de ser expressiva a produção de frutas $(90,41 \%)$ e hortaliças $(86,63 \%)$.

A principal atividade econômica dos pesquisados é a pecuária leiteira, sendo que $86,44 \%$ das famílias visitadas criam bovinos, sendo que desse total, para 74,50\% das famílias investigadas estes têm por finalidade o leite. $\mathrm{O}$ cultivo de milho e cana-de-açúcar são utilizados, sobretudo, para a suplementação dos animais. Já a produção de mandioca, frutas, legumes e hortaliças e a criação de suínos e galináceos são destinados, principalmente, para o consumo familiar e o excedente é comercializado. 
Nessas comunidades rurais, a produção para o consumo familiar é essencial para a reprodução social do grupo, pois as famílias conseguem maior autonomia frente ao contexto social e econômico em que estas unidades de produção e famílias estão inseridas. Com esta produção assegurada, as famílias ficam menos dependentes do mercado.

Verificou-se que a participação nas feiras livres constituiu uma importante estratégia de reprodução social para os agricultores familiares das comunidades pesquisadas, sendo uma possibilidade de agregar valor em seus produtos. Nessas comunidades rurais, 9,29\% dos pesquisados participam das feiras e os produtos comercializados são: verduras, legumes, frutas, frangos caipira e produtos oriundos da produção caseira, como farinha de mandioca, polvilho, queijos, requeijão, doces, rapadura, salgados (coxinhas, pasteis, quibes etc.), caldos e sucos.

Nas comunidades pesquisadas, apenas $36,25 \%$ dos pesquisados recorrem a financiamentos e/ou empréstimos, sendo que destes: 96,87\% informaram que são provenientes do Pronaf e 10,75\% participam do PNAE. Apesar do baixo número de beneficiários do Pronaf e PNAE nessas comunidades, destaca-se que essas políticas têm contribuído para a manutenção da atividade produtiva e o melhoramento das condições de vida no espaço rural de Catalão.

Acredita-se que o acesso e a participação nas políticas públicas destinadas à agricultura familiar contribuem para o desenvolvimento das atividades agropecuárias. Assim, essas políticas são importantes para a reprodução social dos agricultores familiares, por que estimula a produção e comercialização de alimentos por meio da agricultura familiar, além de gerar renda, proporciona a diversidade e oferta de alimentos de qualidade aos alunos atendidos. Acrescenta-se o menor custo com transporte, confiabilidade do produto e valorização dos hábitos regionais.

\section{REFERÊNCIAS}

ABRAMOVAY, Ricardo et al. Agricultura familiar e sucessão profissional: novos desafios. In: CONGRESSO BRASILEIRO DE ECONOMia E SOCIOLOGIA RURAL, 39., 2001, Recife. Anais... Recife: Universidade Federal de Pernambuco, 2001. p. 1-10. Disponível em: <http://www.gp.usp.br/files/denru_sucessao.pdf>. Acesso em: 31 dez. 2013. 
ALVES, José. A dinâmica agrária do município de Ortigueira (PR) e a reprodução social dos produtores familiares: uma análise das comunidades rurais de Pinhalzinho e Vila Rica. 2004. 316 f. Dissertação (Mestrado em Geografia) - Faculdade de Ciências e Tecnologia, Presidente Prudente. 2004.

BLUM, Rubens. Agricultura familiar: um estudo preliminar da definição, classificação e problemática. In: TEDESCO, João Carlos. (Org.). Agricultura familiar: realidades e perspectivas. 3. ed. Passo Fundo: UPF, 2001. p. 57-104.

BONI, Valdete. Produtivo ou reprodutivo: o trabalho das mulheres nas agroindústrias familiares - um estudo na região Oeste de Santa Catarina. 2005. 99 f. Dissertação (Mestrado Sociologia Política) - Centro de Filosofia e Ciências Humanas, Universidade Federal de Santa Catarina, Florianópolis, 2005.

BOURDIEU, Pierre. Razões práticas: sobre a teoria da ação. Tradução Maria Corrêa. Campinas: Papirus, 1996.224 p.

BOURDIEU, Pierre. Stratégies de reproduction et modes de domination. In: Actes de la recherche en sciences sociales, v. 105, p. 3-12, décembre 1994. Disponível em: <http://www.persee.fr/web/revues/home/prescript/article/arss_03355322_1994_num_105_1_3118>.Acesso em: 30 nov. 2013.

BRASIL, Lei n. 11.326, de 24 de julho de 2006. Disponível em: <http://www.planalto.gov.br/ccivil_03/_ato20042006/2006/lei/l11326.htm>. Acesso em: 30 abr. 2014.

BRUMER, Anita. Gênero e agricultura: a situação da mulher na agricultura do Rio Grande do Sul. Estudos Feministas. Florianópolis, v. 12, n. 1, p. 205-227, jan./abr. 2004. Disponível em: <http://www.scielo.br/pdf/ref/v12n1/21699>. Acesso em: 18 dez. 2015.

CARNEIRO, Maria José. Herança e gênero entre agricultores familiares. Revista Estudos Feministas, Florianópolis, v. 9, n. 1, p. 22-55, 2001. Disponível em: <http://www.scielo.br/pdf/ref/v9n1/8602.pdf>. Acesso em: 11 mar. 2014.

CAUME, David José. A agricultura familiar no estado de Goiás. 2. ed. Goiânia: Ed. UFG, 2005. 72 p. (Coleção Quíron).

GARCIA, Franco María. A luta pela terra sob enfoque de gênero: os lugares da diferença no Pontal do Paranapanema. 2004. 216 f. Tese (Doutorado em Geografia) - Faculdade de Ciência e Tecnologia, Universidade Estadual Paulista Júlio de Mesquita Filho, Presidente Prudente, 2004. Disponível em:

<http://base.repositorio.unesp.br/bitstream/handle/11449/102966/garcia_mf_dr_prud.pdf?sequence=1\&isAllowed=y > Acesso em: 18 dez. 2015.

GAZOLLA, Marcio; SCHNEIDER, Sergio. A produção da autonomia: os "papeis" do autoconsumo na reprodução social dos agricultores familiares. Estud.soc.agric., Rio de Janeiro, v. 15, n. 1, p. 89-122, 2007. Disponível em: $<$ r1.ufrrj.br/esa/V2/ojs/index.php/esa/article/download/283/279>. Acesso em: 17 dez. 2015

GRISA, Catia; GAZOLLA, Marcio; SCHNEIDER, Sergio. A “produção invisível” na agricultura familiar: autoconsumo, segurança alimentar e políticas públicas de desenvolvimento rural. AGROALIMENTARIA, v. 16, n. 31, p. 65-79, jul./dez., 2010. Disponível em: <http://www.ufrgs.br/pgdr/arquivos/786.pdf>. Acesso em: 17 dez. 2015.

GRISA, Catia; SCHNEIDER, Sergio. "Plantar pro gasto": a importância do autoconsumo entre famílias de agricultores do Rio Grande do Sul. RER, Piracicaba, v. 46, n. 2, p. 481-515, abr./jun. 2008. Disponível em: <http://www.scielo.br/pdf/resr/v46n2/v46n2a08.pdf>. Acesso em: 17 dez. 2015.

GUIMARÃES, Roberli Ribeiro. As estratégias de resistência camponesa: o movimento camponês popular na comunidade Ribeirão em Catalão (GO). 2010. 166 f. Dissertação (Mestrado em Geografia) - Campus Catalão, Universidade Federal de Goiás, Catalão, 2010.

LAMARCHE, H. (Coord.). Agricultura familiar: comparação internacional. Tradução de Ângela M. N. Tijiwa. Campinas: Unicamp, 1993. v. 1-2. (Coleção Repertórios). 
MENDES, Estevane de Paula Pontes. A produção rural familiar em Goiás: as comunidades rurais no município de Catalão. 2005. 294 f. Tese (Doutorado em Geografia) - Faculdade de Ciências e Tecnologia, Universidade Estadual Paulista, Presidente Prudente, 2005.

REDIN, Ezequiel. Entre o produzir e o reproduzir na agricultura familiar fumageira de Arroio do Tigre/RS. $2011.261 \mathrm{f}$. Dissertação (Mestrado em Extensão Rural) - Universidade Federal de Santa Maria, Santa Maria, 2011.

SANT'ANA, Antônio Lázaro. Raízes na terra: as estratégias dos agricultores familiares de três munícipios da Mesorregião de São José do Rio Preto (SP). 2003. 246 f. Tese (Doutorado em Sociologia) - Faculdade de Ciências e Letras, Universidade Estadual Paulista, Araraquara, 2003.

SCHNEIDER, Sérgio. Teoria social, agricultura familiar e pluriatividade. Revista Brasileira de Ciências Sociais, v. 18, n. 51, p. 99-121, fev. 2003. Disponível em: <http://www.scielo.br/pdf/rbcsoc/v18n51/15988.pdf>. Acesso em: 26 out. 2013.

SILVA, José Graziano da. Velhos e novos mitos do rural brasileiro. Estudos Avançados, v. 15 (43), p. 37-50, 2001. Disponível em: <http://www.scielo.br/pdf/ea/v15n43/v15n43a05.pdf>. Acesso em: 18 jun. 2014.

TEDESCO, João Carlos (Org.). Agricultura familiar: realidades e perspectivas. 3. ed. Passo Fundo: UPF, 2001. 405 p.

TEDESCO, João Carlos. Terra, trabalho e família: racionalidade produtiva e ethos camponês. Passo Fundo: EDIUPF, 1999. $331 \mathrm{p}$.

WANDERLEY, Maria de Nazareth Baudel. Agricultura familiar e campesinato: rupturas e continuidade. Estudos Sociedade e Agricultura, n. 21, p. 42-61, out. 2013. Disponível em:

<http://r1.ufrrj.br/esa/V2/ojs/index.php/esa/article/view/238>. Acesso em: 26 out. 2013. 